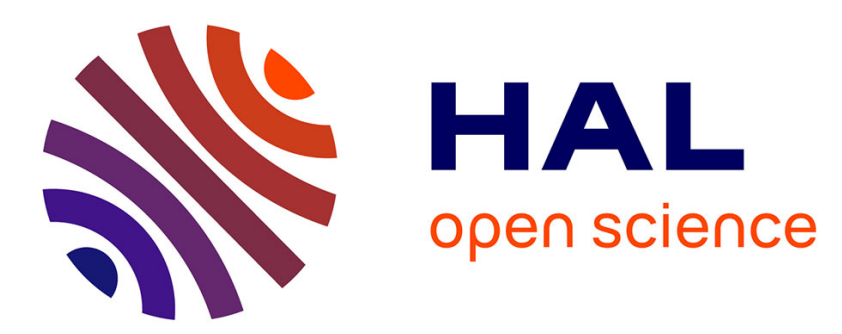

\title{
Exploring the relationships between tobacco smoking and schizophrenia in first-degree relatives.
}

Aziz Ferchiou, Andrei Szöke, Audrey Laguerre, Alexandre Méary, Marion

Leboyer, Franck Schürhoff

\section{- To cite this version:}

Aziz Ferchiou, Andrei Szöke, Audrey Laguerre, Alexandre Méary, Marion Leboyer, et al.. Exploring the relationships between tobacco smoking and schizophrenia in first-degree relatives.. Psychiatry Research, 2012, 200 (2-3), pp.674-8. 10.1016/j.psychres.2012.07.054 . inserm-00797600

\section{HAL Id: inserm-00797600 https://www.hal.inserm.fr/inserm-00797600}

Submitted on 6 Mar 2013

HAL is a multi-disciplinary open access archive for the deposit and dissemination of scientific research documents, whether they are published or not. The documents may come from teaching and research institutions in France or abroad, or from public or private research centers.
L'archive ouverte pluridisciplinaire HAL, est destinée au dépôt et à la diffusion de documents scientifiques de niveau recherche, publiés ou non, émanant des établissements d'enseignement et de recherche français ou étrangers, des laboratoires publics ou privés. 
Exploring the relationships between tobacco smoking and schizophrenia in first-degree relatives

\author{
Aziz Ferchiou ${ }^{\text {a,b,c }}$, \\ Andrei Szöke ${ }^{\text {a,b,c }}$, \\ Audrey Laguerre ${ }^{\text {a,b,c }}$, \\ Alexandre Méary ${ }^{\text {a,b,c }}$, \\ Marion Leboyer ${ }^{\text {a,b,c }}$, \\ Franck Schürhoff ${ }^{\text {a,b,c }}$ *,
}

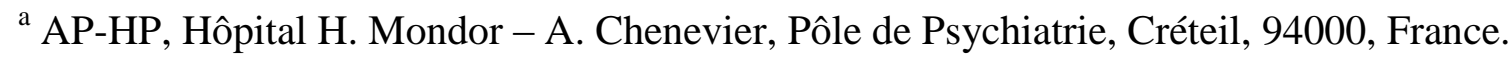

${ }^{\mathrm{b}}$ INSERM U955, Equipe 15, IMRB, Créteil, F-94000, France.

${ }^{\mathrm{c}}$ Université Paris - Est, Faculté de Médecine, Créteil, 94000, France.

"Correspondence should be sent to:

Franck Schürhoff, M.D ; PhD.

Pôle de Psychiatrie du CHU de Créteil

Groupe Hospitalier Mondor - Chenevier

40 rue de Mesly

94000 CRETEIL, France

Tel: (33 1) 49813051

Fax: (33 1) 49813059

E-mail: franck.schurhoff@inserm.fr

Word count: 4815

Table: 3 


\begin{abstract}
Up to $90 \%$ of individuals with schizophrenia suffer from nicotine dependence. Both schizophrenia and nicotine consumption have strong genetic components, which may overlap. The relationship between schizophrenia and nicotine dependence remains unclear, due in part to confounding factors. Studies of the relationship between nicotine consumption and milder schizophrenia-related phenotypes, such as schizotypy, in first-degree relatives of individuals with schizophrenia could help to better understand the relationship between smoking and schizophrenia while avoiding such confounders. We assessed the proportion of smokers, their level of nicotine dependence and their level of schizotypy in a sample of 98 first-degree relatives of schizophrenic subjects and 110 healthy controls. Partial correlation analysis was used to assess the relationship between schizotypal dimensions and smoking dependence. The prevalence of smoking and nicotine dependence levels were higher in the relatives than in the healthy control group. We found no relationship between nicotine dependence and the magnitude of schizotypal features in either group. Our results support the hypothesis that the relationship between schizophrenia and smoking is largely mediated by common familial factors, which may be genetic.
\end{abstract}

Keywords: nicotine; smoking; schizotypy; schizophrenia; genetic; relatives. 


\section{Introduction}

Individuals with schizophrenia tend to be heavy smokers. Despite the smoking cessation programs and anti-smoking campaigns implemented in many countries, up to $90 \%$ of schizophrenic subjects smoke cigarettes and are nicotine dependent (De Leon and Diaz, 2005). One of the hypotheses most frequently put forward to explain the relationship between smoking and schizophrenia is that patients may use smoking as a form of self-medication to decrease the symptoms of schizophrenia or the side effects of treatment.

Convincing data have been obtained indicating that nicotine may improve sensory gating abnormalities (Adler et al., 1993), smooth pursuit eye movements (Olincy et al., 2003) and cognitive deficits in schizophrenic subjects (Ochoa and Lasalde-Dominicci, 2007). Tobacco smoking has also been shown to reduce the side-effects of antipsychotic medication by improving dopamine release in the nigrostriatum or inducing metabolic enzymes that decrease the levels of antipsychotic drugs in the blood (Aguilar et al., 2005). Several studies have shown that the level of nicotine dependence is correlated with either positive (Ziedonis et al., 1994; De Leon et al., 2006) or negative (Patkar et al., 2002) symptoms. These findings led to the suggestion that schizophrenic subjects self-medicate with nicotine, mostly to alleviate positive and negative symptoms (Lavin et al., 1996), but also to relieve symptoms of depression and anxiety (Glynn and Sussman, 1990, Taiminen et al., 1998, Herran et al., 2000). However, studies systematically examining the relationship between tobacco use and particular symptom dimensions or antipsychotic side-effects in schizophrenia patients have yielded inconsistent findings, despite these promising neurobiological rationales. Some studies have higher levels of positive and/or negative symptoms in schizophrenic patients that smoke than in those that do not (Ziedonis et al., 1994; Fukui et al., 1995; Beratis et al., 2001; Patkar et al., 2002), whereas others have found no relationship between smoking and schizophrenia symptoms (Dalack et al., 1999; Addington et al., 1998; Herran et al., 2000; 
Aguilar et al., 2005; Fatemi et al., 2005), and still others (Arias et al., 1997; Beratis et al., 2001) have reported negative symptoms to be inversely correlated with nicotine dependence.

There may be many reasons for these discrepancies, including the heterogeneity of the populations studied (i.e., severe vs. less severe forms of schizophrenia, acute vs. chronic forms, or inpatients vs. outpatients), the lack of continuous scale for the measurement of dependence (subjects are often classified as heavy, mild or non-smokers), the use of inadequate measurements of nicotine dependence for schizophrenic patients (Steinberg et al., 2005), and the influence of pharmacological treatment (McEvoy et al., 1995).

However, these conflicting results also suggest that self-medication is not the only explanatory hypothesis and that schizophrenic patients smoke due to a combination of factors including self-medication and genetic susceptibility. It has been suggested that some susceptibility genes for schizophrenia and nicotine dependence are common to these two conditions (Dalack et al., 1998), and there is genetic evidence to support this hypothesis. Strong genetic components have been found for both predisposition to tobacco use (Saccone et al., 2007) and susceptibility to schizophrenia (Owen et al., 2004; Harrison and Weinberger, 2005). Several nicotinic receptor gene variants have recently been reported to be associated with an increase in the risk of nicotine dependence (Saccone et al., 2007). Faraone et al. (2004) also found evidence for linkage between smoking in schizophrenia and the nicotinic receptor $\alpha 2$ (8p21), $\beta 2$ (1q21), and $\alpha 7$ (15q14) subunit genes. The locus of the $\alpha 7$ subunit gene has also been linked to the P50 deficit in schizophrenia, with a LOD score of 5.3 (Freedman et al., 1997). Linkage between this locus and schizophrenia has also been demonstrated in a number of other studies (Freedman et al., 2001a, 2001b; Tsuang et al., 2001; Liu et al., 2001).

By studying nicotine consumption in individuals with a high genetic risk of developing schizophrenia, it may be possible to avoid some of the methodological problems of previous 
studies and to improve our understanding of the relationship between smoking and schizophrenia. Studies of relatives of schizophrenic subjects are free from several problems that can potentially confound studies in schizophrenic patients, including the effects of longterm and (usually) ongoing medication, multiple hospital admissions or institutionalization, prolonged functional impairment due to chronic disease and a deterioration of social skills. Only a few studies have investigated nicotine consumption in the first-degree relatives of schizophrenic subjects. This group has been reported to contain a higher proportion of smokers than control groups (Lyons et al., 2002; Smith et al., 2008). Studies of the relationship between nicotine consumption and schizotypy in the relatives of schizophrenic patients could thus provide indirect information about the relationship between smoking and schizophrenic symptoms. Indeed, genetic and developmental links have already been found between schizotypy and schizophrenia (Kendler et al., 1995), and these two conditions are composed of the same symptomatic dimensions (Vollema and van den Bosch, 1995). Furthermore, the symptoms in schizophrenic probands are predictive of similar schizotypal traits in relatives (Mata et al., 2000; Fanous et al., 2001).

To our knowledge, only one study has investigated the relationship between nicotine dependence and schizotypy in a sample of 42 first-degree relatives of schizophrenic probands, most of whom were African-American. The authors found a positive relationship between smoking status and the level of schizotypy in relatives (Esterberg et al., 2007).

We aimed to replicate the results of Esterberg et al. (2007) in a large Caucasian sample. We therefore investigated the relationship between specific dimensions of schizotypy and tobacco smoking in unaffected first-degree relatives of schizophrenic subjects and in healthy controls. We assessed the proportion of smokers and the severity of nicotine dependence in our two samples, and then investigated the association between schizotypal traits (positive, negative and disorganized) and the severity of nicotine dependence. 


\section{Method}

\subsection{Subjects}

We recruited Caucasian probands meeting the DSM-IV-TR (APA, 2000) criteria for schizophrenia, consecutively admitted to a university hospital (Psychiatry Department, ParisEst University). For confirmation of the diagnosis, patients were interviewed directly by an experienced psychiatrist using the French version of the Diagnostic Interview for Genetic Studies (DIGS), which has a high inter-rater and test-retest reliability (Nurnberger et al., 1994; Preisig et al., 1999).

Unaffected first-degree relatives of the probands were contacted and asked to participate in the study. We recruited healthy Caucasian controls from blood donors. Relatives and controls were also interviewed with the French version of the DIGS to confirm the absence of schizophrenia. Controls were interviewed with the FIGS (Family Interview for Genetic Studies) (Maxwell, 1992) to confirm the absence of psychiatric disorders in their family history.

None of the subjects had a history of neurological disease, or was currently dependent on any substance other than nicotine, as evaluated with the DIGS, which has a detailed section for assessing current and past episodes of substance abuse or dependence (alcohol, cocaine, cannabis, hallucinogens, opiates, sedatives, inhalants, etc.). Written informed consent was obtained from each subject.

\subsection{Measurements}

Information about age, sex, level of education and other demographic characteristics was collected from the DIGS for each subject. 
We used the validated French translation of the Schizotypal Personality Questionnaire (SPQ) (Raine, 1991; Dumas et al., 1999, 2000) to assess schizotypal dimensions (positive, negative and disorganized dimensions). Subjects also completed the French translation of the Fagerström Test for Nicotine Dependence (FTND) (Heatherton et al., 1991; Etter et al., 1999). This six-item instrument assesses nicotine dependence: it is widely used in the general population and has been shown to be highly reliable and valid (Heatherton et al., 1991). Former smokers were included in the non-smoker group for two main reasons: 1) former smokers were considered to be non-smokers in previous studies; and 2) smoking dependence was evaluated with the Fagerström test, which investigates current dependence.

For inclusion in the study, relatives and controls had to be euthymic as evaluated with the MADRS (Montgomery and Asberg, 1979) and the Bech-Rafaelson (Beck et al., 1978) mania rating scale (MAS).

\subsection{Statistical analysis}

Differences between groups (controls and relatives) were assessed with the Mann-Whitney test for continuous variables and with chi-squared or Fischer's exact tests for discrete variables. Partial correlation analysis (Spearman's rank correlation coefficient) was carried out to investigate the relationships between schizotypal dimensions and smoking dependence, making it possible to control for the potentially confounding influences of sex, age and level of education.

\section{Results}


The final samples consisted of 98 first-degree relatives of schizophrenic subjects and 110 healthy controls. Most of the relatives were the parents of patients (70.4\%). All subjects were euthymic at the time of the study, with MADRS and MAS scores $<5$. The demographic and clinical characteristics of these subjects are displayed in Table 1. The relatives were older than the controls $(51.7 \pm 14.7$ vs. $41.9 \pm 11.7 ; p<0.0001)$. Sex ratios were similar for relatives and controls (48.9\% and 55.4\% men, respectively). The highest completed school grade (level of education) was recorded, according to the usual conventions (Pichot et al., 1993) as a trichotomous variable $(1=$ elementary school; $3=$ completion of high school or above; $2=$ intermediate between 1 and 3). However, we finally decided to merge levels 1 and 2 because level 1 was infrequent in both groups. Level of education did not differ significantly between the two samples $(p=0.33)$.

The proportion of smokers were more higher among the relatives than among the controls (44.9\% vs. $23.6 \% ; p=0.001)$ and nicotine dependence was greater among the relatives than among the controls that smoked, as shown by FTND scores $(2.66 \pm 2$ vs. $1.65 \pm 1.99 ; p=$ 0.04) (Table 1).

Schizotypy levels were low, with similar values obtained for the two groups (11.36 \pm 10.9 for controls and $10.58 \pm 7.98$ for relatives) (Table 1).

\section{INSERT TABLE 1}

Mean schizotypal (SPQ) scores did not differ between smokers and non-smokers in either group $(9.84 \pm 9.1$ vs. $12.59 \pm 12.2$ in relatives; $10.7 \pm 8.6$ vs. $10.74 \pm 7.8$ in controls) (Table 2). 
We found no correlation between nicotine dependence and SPQ score (full score, or scores for the positive, negative and disorganized dimensions) in either relatives or healthy controls (Table 3).

\section{INSERT TABLE 3}

\section{Discussion}

The goal of our study was to examine the relationship between nicotine dependence and schizotypy in a sample of healthy first-degree relatives of schizophrenic patients and healthy controls without a family history of schizophrenia. The only previous study of this relationship, to our knowledge, is that of Esterberg et al. (2007), which dealt with a smaller sample.

One of the most striking findings of this study was the differences in the proportion of smokers and the level of nicotine dependence between the two groups. The proportion of smokers was higher and the level of nicotine dependence was greater in first-degree relatives than in controls. The proportion of smokers in our control group is similar to that reported for the general population (20-30\%) (Lyons et al., 2002). The proportion of smokers in the group of relatives was intermediate between that in samples of schizophrenic patients $(70 \%$ or greater) and that in the general population. Our results are consistent with those of previous studies (Lyons et al., 2002; Smith et al., 2008). However, Esterberg et al. (2007) reported a higher proportion of smokers in their control group, with similar levels of nicotine dependence in the two groups. The prevalence of smoking among healthy controls $(66 \%)$ in the study by Esterberg et al. was much higher than the prevalence of smoking in the general 
population (20-30\%), suggesting a possible recruitment biases. Furthermore, $90.2 \%$ of the subjects included in their sample were African-American, whereas our sample was entirely Caucasian. These two ethnic groups metabolize nicotine differently and have different specific smoking habits, with African-American reported to have higher levels of nicotine dependence and lower smoking cessation rates despite smoking fewer cigarettes per day (Benowitz, 2008; Gandhi et al., 2009). The level of nicotine dependence in study by Esterberg et al. may therefore have been underestimated. Our results suggest that familial - possibly genetic - factors may make a major contribution to the relationship between schizophrenia and smoking. This hypothesis is clearly supported by several lines of genetic, biological and clinical evidence. The heritability of smoking behavior (Spitz et al., 1998; Shields et al., 1998; Kendler et al., 1999) and the linkage demonstrated between schizophrenia and specific nicotinic receptor genes or nicotine-metabolizing enzyme genes confirm this genetic susceptibility (Freedman et al., 1997, 2001b; Leonard et al., 2002; Yoshimasu and Kiyohara, 2003; Leonard et al., 2007). Furthermore, genetic linkage studies of smoking in schizophrenia have shown that these linkage sites coincide with replicated sites of linkage in schizophrenia (Faraone et al., 2004). However, environmental factors common to schizophrenic patients and their relatives may contribute to the higher prevalence of smoking in these two groups. The hypothesis that relatives are mimicking the behaviour of schizophrenic subjects by smoking is unlikely, as most of the relatives in our sample were parents, who presumably started smoking before the probands.

We found no correlation between either smoking status or nicotine dependence and the level of schizotypy in either group of subjects. Several studies have reported a positive correlation between schizotypy and smoking status in the general population (Williams et al., 1996; Larrison et al., 1999; Joseph et al., 2003). Interestingly, Esterberg et al. (2007) found a positive relationship between smoking status and the level of schizotypy in their sample of 
first-degree relatives of schizophrenic subjects, but not in the control group. Our findings, conducted in a larger sample, do not support the hypothesis that relatives use nicotine as a form of "self-medication" to improve schizotypal traits. Unaffected first-degree relatives probably carry schizophrenia susceptibility genes, but, typically, do not suffer from the confounding effects of chronic illness and ongoing treatment. They are therefore, ideal subjects for studies of the possible trait-related markers of susceptibility to schizophrenia. Our results argue against the self-medication theory of smoking in schizophrenia, consistent with previous findings, including the observation that $90 \%$ of schizophrenic subjects begin smoking before they become ill, even before the prodromal phase (De Leon et al., 2002; Gurpegui et al., 2005). The convincing evidence that smoking does not greatly alleviate schizophrenic symptoms is probably the absence of major changes to schizophrenic symptom scores in most trials in which schizophrenic subjects either stopped smoking or smoked less (Dalack et al., 1999; Evins et al., 2001, 2005; Smith et al., 2002; Fatemi et al., 2005).

Our study has several limitations. Firstly, the relatives had SPQ scores that were similar to those of the controls and therefore, lower than expected. There are several possible reasons for this. The relatives of schizophrenic patients may be more defensive in their responses to schizotypy questionnaires (Calkins et al., 2004) and there may be a selection effect, with only relatives with fewer schizotypal traits agreeing to participate in research studies. Secondly, although all relatives were euthymic at the time of assessment, we cannot not rule out the hypothesis that they smoke to improve their mood (Berlin et al., 1995; Lerman et al., 1998), as being the parent of a schizophrenic patient may lead to depressive states. Similarly, we could not exclude the possibility of relatives smoking to improve cognitive deficits or due to a low socio-economic status, as shown for schizophrenic subjects. Thirdly, we did not take into account the fact that the relatives were older than the controls, and have therefore probably been exposed to more antismoking campaigns. 
Our results provide support for the hypothesis that familial factors increase the prevalence of smoking in first-degree relatives of schizophrenic subjects, who have a "high genetic risk" of schizophrenia. If it can be confirmed that genetic factors make people at risk of schizophrenia more likely to smoke, this would have major implications for our understanding of the aetiology of schizophrenia.

The relatives of schizophrenic patients are at greater risk of becoming cigarette smokers. They therefore also have a greater risk of developing chronic health problems. Efforts should therefore be made to prevent nicotine dependence in these relatives and, if necessary, to help them quit smoking if they have already started.

Moreover, as some studies have suggested that nicotine may play a role in conversion to psychosis (Kristensen and Cadenhead, 2007) and that heavier smoking is associated with a greater risk of schizophrenia (Weiser et al., 2004), special psychiatric monitoring could be proposed for young heavy smokers related to schizophrenic subjects, who are at greater risk of developing schizophrenia. 


\section{Acknowledgments}

We thank M.J. Pereira-Gomes and E. Abadie for technical assistance.

We also thank the FondaMental foundation for technical support. 


\section{References}

Addington, J., el-Guebaly, N., Campbell, W., Hodgins, D.C., Addington, D., 1998. Smoking cessation treatment for patients with schizophrenia. American Journal of Psychiatry 155, 974-976.

Adler, L.E., Hoffer, L.D., Wiser, A., Freedman, R., 1993. Normalization of auditory physiology by cigarette smoking in schizophrenic patients. American Journal of Psychiatry 150, 1856-1861.

Aguilar, M.C., Gurpegui, M., Diaz, F.J., de Leon, J., 2005. Nicotine dependence and symptoms in schizophrenia: Naturalistic study of complex interactions. British Journal of Psychiatry 186, 215-221.

American Psychiatric Association, 2000. Diagnostic and statistical manual of mental disorders DSMIV-TR fourth edition (Text Revision). American Psychiatric Press, Washington, D.C.

Arias, H.F., Padin Calo, J.J., Fernandez Gonzalez, M.A., 1997. Drug use and dependence in schizophrenia. Actas Luso-Espanolas de Neurologia, Psyquiatria y Ciencias Afines 25, 379389.

Bech, P., Rafaelsen, O.J., Kramp, P., Bolwig, T.G., 1978. The mania rating scale: scale construction and inter-observer agreement. Neuropharmacology 17, 430-431.

Benowitz, N.L., 2008. Clinical pharmacology of nicotine: implications for understanding, preventing, and treating tobacco addiction. Clinical Pharmacology \& Therapeutics 83, 531-541.

Beratis, S., Katrivanou, A., Gourzis, P., 2001. Factors affecting smoking in schizophrenia. Comprehensive Psychiatry 42, 393-402.

Berlin, I., Said, S., Spreux-Varoquaux, O., Olivares, R., Launay, J.M., Puech, A.J., 1995. Monoamine oxidase A and B activities in heavy smokers. Biological Psychiatry 38,756-761.

Calkins, M.E., Curtis C.E., Grove, W.M., Iacono, W.G., 2004. Multiple dimensions of schizotypy in first-degree biological relatives of schizophrenia patients. Schizophrenia Bulletin 30, 317325.

Dalack, G.W., Healy, D.J., Meador-Woodruff, J.H., 1998. Nicotine dependence in schizophrenia: clinical phenomena and laboratory findings. American Journal of Psychiatry 155, 1490-1501. 
Dalack, G.W., Becks, L., Hill, E., Pomerleau, O.F., Meador-Woodruff, J.H., 1999. Nicotine withdrawal and psychiatric symptoms in cigarette smokers with schizophrenia. Neuropsychopharmacology 21, 195-202.

de Leon, J., Diaz, F.J., Rogers, T., Browne, D., Dinsmore, L., 2002. Initiation of daily smoking and nicotine dependence in schizophrenia and mood disorders. Schizophrenia Research 56, 47-54. de Leon, J., Diaz, F.J., 2005. A meta-analysis of worldwide studies demonstrates an association between schizophrenia and tobacco smoking behaviours. Schizophrenia Research 76, 135157.

de Leon, J., Diaz, F.J., Aguilar, M.C., Jurado, D., Gupergui, M., 2006. Does smoking reduce akathisia? Testing a narrow version of the self-medication hypothesis. Schizophrenia Research 86, 256-268.

Dumas, P., Rosenfeld, F., Saoud, M., Dalery, J., d'Amato, T., 1999. Traduction et adpatation Française du questionnaire de personnalité schizotypique de Raine. Encéphale 25, 315-322.

Dumas, P., Bouafia, S., Gutknecht, C., Saoud, M., Dalery, J., d’Amato, T., 2000. Validation de la version française du questionnaire de personnalité schizotypique de Raine - approche catégorielle et dimensionnelle des traits de personnalité schizotypique dans une population d'étudiants. Encéphale 26, 23-29.

Esterberg, M.L., Jones, E.M., Compton, M.T., Walker, E.F., 2007. Nicotine consumption and schizotypy in first-degree relatives of individuals with schizophrenia and non-psychiatric controls. Schizophrenia Research 97, 6-13.

Etter, J.F., Duc, T.V., Perneger, T.V., 1999. Validity of the Fagerström test for nicotine dependence and of the Heaviness of Smoking Index among relatively light smokers. Addiction 94, 269281.

Evins, A.E., Mays, V.K., Rigotti, N.A., Tisdale, T., Cather, C., Goff, D.C., 2001. A pilot trial of bupropion added to cognitive behavioral therapy for smoking cessation in schizophrenia. Nicotine \& Tobacco Research 3, 397-403.

Evins, A.E., Deckersbach, T., Cather, C., Freudenreich, O., Culhane, M.A., Henderson, D.C., Green, M.F., Schoenfeld, D.A., Rigotti, N.A., Goff, D.C., 2005. Independent effects of tobacco 
abstinence and bupropion on cognitive function in schizophrenia. Journal of Clinical Psychiatry 66, 1184-1190.

Fanous, A., Gardner, C., Walsh, D., Kendler, K.S., 2001. Relationship between positive and negative symptoms of schizophrenia and schizotypal symptoms in nonpsychotic relatives. Archives of General Psychiatry 58, 669-673.

Faraone, S.V., Su, J., Taylor, L., Wilcox, M., Van Eerdewegh, P., Tsuang, M.T., 2004. A novel permutation testing method implicates sixteen nicotinic acetylcholine receptor genes as risk factors for smoking in schizophrenia families. Human Heredity 57, 59-68.

Fatemi, S.H., Stary, J.M., Hatsukami, D.K., Murphy, S.E., 2005. A double-blind placebo-controlled cross over trial of bupropion in smoking reduction in schizophrenia. Schizophrenia Research $76,353-356$

Freedman, R., Coon, H., Myles-Worsley, M., Orr-Urtreger, A., Olincy, A., Davis, A., Polymeropoulos, M., Holik, J., Hopkins, J., Hoff, M., Rosenthal, J., Waldo, M.C., Reimherr, F., Wender, P., Yaw, J., Young, D.A., Breese, C.R., Adams, C., Patterson, D., Adler, L.E., Kruglyak, L., Leonard, S., Byerley, W., 1997. Linkage of a neurophysiological deficit in schizophrenia to a chromosome 15 locus. Proceedings of the National Academy of Sciences, USA. $94,587-592$.

Freedman, R., Leonard, S., Gault, J.M., Hopkins, J., Cloninger, C.R., Kaufmann, C.A., Tsuang, M.T., Farone, S.V., Malaspina, D., Svrakic, D.M., Sanders, A., Gejman, P., 2001. Linkage disequilibrium for schizophrenia at the chromosome 15q13-14 locus of the alpha7-nicotinic acetylcholine receptor subunit gene (CHRNA7). American Journal of Medical Genetics 105, 20-22.

Freedman, R., Leonard, S., Olincy, A., Kaufmann, C.A., Malaspina, D., Cloninger, C.R., Svrakic, D., Faraone, S.V., Tsuang, M.T., 2001. Evidence for the multigenic inheritance of schizophrenia. American Journal of Medical Genetics 105, 794-800.

Fukui, K., Kobayashi, T., Hayakawa, S., Koga, E., Okazaki, S., Kawashima, Y., et al., 1995. Smoking habits of chronic schizophrenics. Japanese Journal of Alcohol Studies and Drug Dependence $30,447-454$ 
Gandhi, K.K., Foulds, J., Steinberg, M.B., Lu, S.E., Williams, J.M., 2009. Lower quit rates among African American and Latino menthol cigarette smokers at a tobacco treatment clinic. International Journal of Clinical Practice 63, 360-367.

Glynn, S.M., Sussman, S., 1990. Why patients smoke. Hospital \& Community Psychiatry 41, 10271028.

Gurpegui, M., Martínez-Ortega, J.M., Aguilar, M.C., Diaz, F.J., Quintana, H.M., de Leon, J., 2005. Smoking initiation and schizophrenia: a replication study in a Spanish sample. Schizophrenia Research 76, 113-118

Harrison, P.J., Weinberger, D.R., 2005. Schizophrenia genes, gene expression, and neuropathology: on the matter of their convergence. Molecular Psychiatry 10, 40-68.

Heatherton, T.F., Kozlowski, L.T., Frecker, R.C., Fagerstrom K.O., 1991. The Fagerström test for nicotine dependence: a revision of the Fagerström Tolerance Questionnaire. British Journal of Addiction 86, 1119-1127.

Herran, A., De Santiago, A., Sandoya, M., Fernandez, M.J., Diez-Manrique, J.F., Vasquez-Barquero, J.L., 2000. Determinants of smoking behaviour in outpatients with schizophrenia. Schizophrenia Research 41, 373-381.

Joseph, S., Manafi, E., Lakovaki, A.M., Cooper, R., 2003. Personality, smoking motivation, and selfefficacy to quit. Personality \& Individual Differences $34,749-758$.

Kendler, K.S., Neale, M.C., Walsh, D., 1995. Evaluating the spectrum concept of schizophrenia in the Roscommon Family Study. American Journal of Psychiatry 152, 749-754.

Kendler, K.S., Neale, M.C., Sullivan, P., Corey, L.A., Gardner, C.O., Prescott, C.A., 1999. A population-based twin study in women of smoking initiation and nicotine dependence. Psychological Medicine 29, 299-308.

Kim, Y.S., Ko, H., Yoon, C., Lee, D.H., Sung, J., 2012. Social determinants of smoking behavior: the healthy twin study, Korea. Journal of Preventive Medicine \& Public Health 45, 29-36.

Kristensen, K., Cadenhead, K., S., 2007. Cannabis abuse and risk for psychosis in a prodromal sample. Psychiatry Research 151, 151-154. 
Larrison, A.L., Briand, K.A., Sereno, A.B., 1999. Nicotine, caffeine, alcohol and schizotypy. Personality \& Individual Differences 27, 101-108.

Lavin, M.R., Siris, S.G., Mason, S.E., 1996. What is the clinical importance of cigarette smoking in schizophrenia? American Journal of Addiction 5, 189-208.

Leonard, S., Gault, J., Hopkins, J., 2002. Association of promoter variants in the $\alpha 7$ nicotine acetylcholine receptor gene with an inhibitory deficit found in schizophrenia. Archives of General Psychiatry 59, 1085-1096.

Leonard, S., Mexal, S., Freedman, R., 2007. Smoking, genetics and schizophrenia: evidence for self medication. Journal of Dual Diagnosis 3, 43-59.

Lerman, C., Caporaso, N., Main, D., Audrain, J., Boyd, N.R., Bowman, E.D., Shields, P.G., 1998. Depression and self-medication with nicotine: the modifying influence of the dopamine D4 receptor gene. Health Psychology 17, 56-62.

Liu, C.M., Hwu, H.G., Lin, M.W., Ou-Yang, W.C., Lee, S.F., Fann, C.S., Wong, S.H., Hsieh, S.H., 2001. Suggestive evidence for linkage of schizophrenia to markers at chromosome 15q13-14 in Taiwanese families. American Journal of Medical Genetics 105, 658-661.

Lyons, M.J., Bar, J.L., Kremen, W.S., Toomey, R., Eisen, S.A., Goldberg, J., Faraone, S.V., Tsuang, M., 2002. Nicotine and familial vulnerability to schizophrenia: a discordant twin study. Journal of Abnormal Psychology 111, 687-693.

Mata, I., Sham, P.C., Gilvarry, C.M., Jones, P.B., Lewis, S.W., Murray, R.M., 2000. Childhood schizotypy and positive symptoms in schizophrenic patients predicts schizotypy in relatives. Schizophrenia Research 44, 129-136.

Maxwell, M.E., 1992. Family Interview for Genetic Studies. Clinical Neurogenetic Branch, Intramural Research Program, NIMH.

McEvoy, J.P., Freudenreich, O., Levin, E.D., Rose, J.E., 1995. Haloperidol increases smoking in patients with schizophrenia. Psychopharmacolgy (Berl) 119, 124-126.

Montgomery, S.A., Asberg, M., 1979. A new depression scale designed to be sensitive to change. Britsh Journal of Psychiatry 134, 382-389. 
Nurnberger, J.I.Jr., Blehar, M.C., Kaufmann, C.A., York-Cooler, C., Simpson, S.G., HarkavyFriedman, J., Severe, J.B., Malaspina, D., Reich, T., 1994. Diagnostic interview of genetic studies. Rationale, unique features and training. NIMH Genetics Initiative. Archives of General Psychiatry 51, 849-859.

Ochoa, E.L.M., Lasalde-Dominicci, J., 2007. Cognitive deficits in schizophrenia: Focus on neuronal nicotinic acetylcholine receptors and smoking. Cellular \& Molecular Neurobiology 27, 609639.

Olincy, A., Johnson, L.L., Ross, R.G., 2003. Differntial effects of cigarette smoking on performance of a smooth pursuit and a saccadic eye movement task in schizophrenia. Psychiatry Research $117,223-236$.

Owen, M.J., Williams, N.M., O'Donovan, M.C., 2004. The molecular genetics of schizophrenia: new findings promise new insights. Molecular Psychiatry 9, 14-27.

Patkar, A.A., Gopalakrishnan, R., Lundy, A., Leone, F.T., Certa, K.M., Weinstein, S.P., 2002. Relationship between tobacco smoking and positive and negative symptoms in schizophrenia. Journal of Nervous \& Mental Disease 190, 604-610.

Pichot, P., Lebeaux, M.O., Penhouët, C., Simon, M., 1993. L'estimation du niveau intellectuel prémorbide à la WAIS-R. Comparaison entre la méthode de Barona et l'ndex de détérioration de Wechsler. Revue Européenne de Psychologie Appliquée 43, 291-301.

Preisig, M., Fenton, B.T., Matthey, M.L., Berney, A., Ferrero, F., 1999. Diagnostic interview of genetic studies (DIGS): inter-rater and test-retest reliability of the French version. European Archives of Psychiatry \& Clinical Neuroscience 249, 174-179.

Raine, A., 1991. The SPQ: A scale for the assessment of schizotypal personality based on DSM-III-R criteria. Schizophrenia Bulletin 17, 556-564.

Saccone, S.F., Hinrichs, A.L., Saccone, N.L., Chase, G.A., Konvicka, K., Madden, P.A., Breslau, N., Johnson, E.O., Hatsukami, D., Pomerleau, O., Swan, G.E., Goate, A.M., Rutter, J., Bertelsen, S., Fox, L., Fugman, D., Martin, N.G., Montgomery, G.W., Wang, J.C., Ballinger, D.G., Rice, J.P., Bierut, L.J., 2007. Cholinergic nicotinic receptor genes implicated in a nicotine 
dependence association study targeting 348 candidate genes with 3713 SNPs. Human Molecular Genetics 16, 36-49.

Shields, P.G., Lerman, C., Audrain, J., Bowman, E.D., Main, D., Boyd, N.R., Caporaso, N.E., 1998. Dopamine D4 receptors and the risk of cigarette smoking in African-Americans and Caucasians. Cancer Epidemiology \& Biomarkers Prevention 7, 453-458.

Smith, M.J., Barch, D.M., Wolf, T.J., Mamah, D., Csernansky, J.G., 2008. Elevated rates of substance use disorders in non-psychotic siblings of individuals with schizophrenia. Schizophrenia Research 106, 294-299.

Smith, R.C., Singh, A., Infante, M., Khandat, A., Kloos, A., 2002. Effects of cigarette smoking and nicotine nasal spray on psychiatric symptoms and cognition in schizophrenia. Neuropsychopharmacology 27, 479-497.

Spitz, M.R., Shi, H., Yang, F., Hudmon, K.S., Jiang, H., Chamberlain, R.M., Amos, C.I., Wan, Y., Cinciripini, P., Hong, W.K., Wu, X., 1998. Case-control study of the D2 dopamine receptor gene and smoking status in lung cancer patients. Journal of the National Cancer Institute 90, 358-363.

Steinberg, M.L., Williams, J.M., Steinberg, H.R., Krejci, J.A., Ziedonis, D.M., 2005. Applicability of the Fagerstrom test for nicotine dependence in smokers with schizophrenia. Addictive Behaviors 30, 49-59.

Taiminen, T.J., Salokangas, R.K., Saarijärvi, S., Niemi, H., Lehto, H., Ahola, V., Syvälahti, E., 1998. Smoking and cognitive deficits in schizophrenia: a pilot study. Addictive Behaviors 23, 263266.

Tsuang, D.W., Skol, A.D., Faraone, S.V., Bingham, S., Young, K.A., Prabhudesai, S., Haverstock, S.L., Mena, F., Menon, A.S., Bisset, D., Pepple, J., Sauter, F., Baldwin, C., Weiss, D., Collins, J., Boehnke, M., Schellenberg, G.D., Tsuang, M.T., 2001. Examination of genetic linkage of chromosome 15 to schizophrenia in a large Veterans Affairs Cooperative Study sample. American Journal of Medical Genetics 105, 662-668.

Vollema, M.G., Van den Bosch, R.J., 1995. The multidimensionality of schizotypy. Schizophrenia Bulletin 21, 19-31. 
Weiser, M., Reichenberg, A., Grotto, I., Yasvitzky, R., Rabinowitz, J., Lubin, G., Nahon, D., Knobler, H.Y., Davidson, M., 2004. Higher rates of cigarette smoking in male adolescents before the onset of schizophrenia: a historical-prospective cohort study. American Journal of Psychiatry $161,1219-1223$.

Williams, J.H., Wellman, N.A., Allan, L.M., Taylor, E., Tonin, J., Feldon, J., Rawlins, J.N.P., 1996. Tobacco smoking correlates with schizotypal and borderline personality traits. Personality \& Individual Differences 20, 267-270.

Yoshimasu, K., Kiyohara, C., 2003. Genetic influences on smoking behaviour and nicotine dependence: a review. Journal of Epidemiology 13, 183-192.

Ziedonis, D.M., Kosten, T.R., Glazer, W.M., Frances, R.J., 1994. Nicotine dependence and schizophrenia. Hospital \& Community Psychiatry 45, 204-206. 